\title{
Small intestinal stricture complicating superior mesenteric vein thrombosis. A study of three cases
}

\author{
C Eugène, D Valla, L Wesenfelder, A Fingerhut, A Bergue, J Merrer, C Felsenheld,
} A Moundji, J-C Etienne

\begin{abstract}
Mesenteric vein thrombosis associated with intestinal stricture, as a consequence of intestinal ischaemia, has only been mentioned twice in published works. The clinical, biological, and morphological aspects as well as the treatment of this morbid association were studied in three patients. In all, a two stage clinical course (initial acute abdominal pain and fever, followed by chronic intestinal obstruction), corresponding to the sequence thrombosis/stricture, was found. $x$ Ray studies showed a regularly contoured intestinal stricture. Surgical resection was required in all three cases for stricture, associated in one case with mesenteric infarction. Anticoagulation treatment was used to preclude recurrence. Increased clinical awareness could lead to the diagnosis of intestinal stricture secondary to mesenteric vein thrombosis more often and at an earlier stage. Treatment consists of evaluation of predisposing features, intestinal resection when necessary, and anticoagulation therapy, as indicated.
\end{abstract}

(Gut 1995; 37: 292-295)

Keywords: mesenteric vascular occlusion, mesenteric veins, thrombosis, jejunum, small bowel obstruction, intestine.

Hepatology and

Gastroenterology Unit

$C$ Eugène

L Wesenfelder

General and Digestive Surgery Unit

A Fingerhut

A Moundji

J-C Etienne

Pathology Department

A Bergue

C Felsenheld

Medical Intensive Care

Unit

J Merrer

Centre Hospitalie

Intercommunal,

Poissy, France

Hepatology and

Gastroenterology Unit,

Pitié Salpétrière

Hospital, Paris,

France

$D$ Valla

Correspondence to:

Professor C Eugène, Centre

Hospitalier Intercommunal,

10 rue du Champ Gaillard,

78303 Poissy Cedex, France.

Accepted for publication

19 December 1994

Case report 1

A 36 year old man was referred to our hospital in November 1990 for acute abdominal pain.
Previous history included cocaine addiction, which ended in 1984. There was no history of thrombosis in the family. Investigations performed in another hospital showed leucocytosis whereas the pancreatic enzymes and hepatic function tests were normal. Ultrasonography and computed tomography were not contributive. Upper gastrointestinal endoscopy showed a congestive gastropathy. Upon admission on 25 November 1990, physical examination was normal. Leucocytosis was still present. The head of the pancreas was found to be heterogeneous on endosonography, computed tomography, and nuclear magnetic resonance. The main pancreatic duct was found to be normal on endoscopic retrograde choliopancreaticography. The biliary duct was not opacified. There was no erosive duodenitis. Ultrasonography and duplex scanning showed thrombosis of the portal vein with cavernoma and splenomegaly. Computed tomography and nuclear magnetic resonance showed that both the portal and superior mesenteric veins were thrombosed, as confirmed by arteriograms, which showed hepatopetal flow in the cavernoma and gastric varices. Colonoscopy showed an adenoma. Haematological tests were negative except for the presence of antiphospholipid antibody, but this abnormality was not found ultimately (see Table II). Heparin therapy was started 1 December 1990. On 21 December, the patient presented with proximal intestinal obstruction. A barium follow through and computed tomography were thought to be consistent with jejunal haematoma. Total parenteral nutrition was started. As these symptoms persisted and a second barium follow through showed a stricture (Fig 1), an exploratory laparotomy was performed on 25 January 1991. A jejunal stricture was found at $30 \mathrm{~cm}$ from the duodenojejunal flexure, associated with adherence to the omentum, which was resected as well. Histopathological study (by

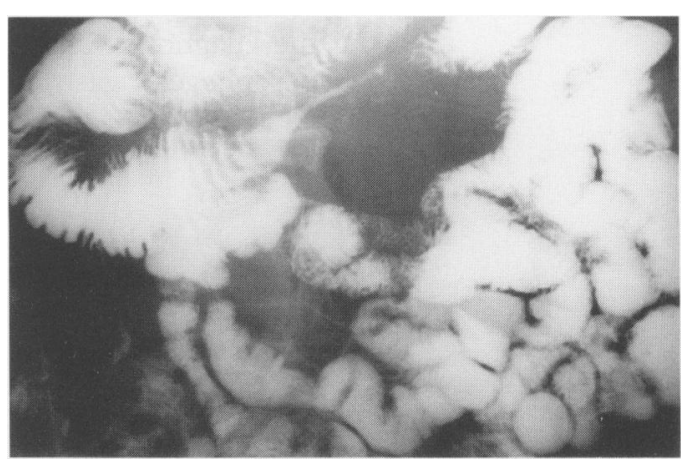

Figure 1: Small intestine follow through showing a long, regularly contoured stricture (case 1). 


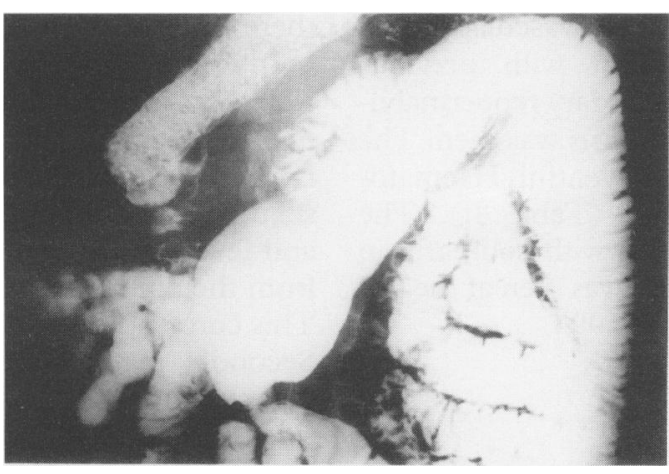

Figure 2: Small intestine follow through showing a short, regularly contoured, jejunal stricture associated with proximal dilatation (case 3).

I Bad Alsamad) showed a $4 \mathrm{~cm}$ ulceration, fibrosis disrupting the architecture of the muscular fibres, and thrombosis of the vessels with mild to moderate recanalisation. There was no haematoma. The patient made an uneventful recovery. Heparin therapy was stopped and replaced by coumarin. No relapse was seen at the last follow up visit at the end of 1993.

\section{Case report 2}

A 46 year old man was admitted to hospital in September 1991 for acute abdominal pain. This patient had taken aspirin for a toothache several days previously. There was no history of thrombosis in the family. Periumbilical pain was associated with dark red blood per anum. The abdomen was tender to examination but without guarding. The white blood count showed neutrophil polymorphonucleosis. Antral and bulbar erosions were found upon upper gastrointestinal endoscopy and disappeared after antisecretory treatment. Colonoscopy and ultrasonography were noncontributive. As abdominal pain persisted, an exploratory laparotomy was performed on 12 November 1991. A $2 \mathrm{~cm}$ stricture was found on the ileum, $20 \mathrm{~cm}$ from the valvule of Bauhin, attached to the bladder by a band. Histopathological examination showed an ulceration with granulomatous inflammatory infiltrate, without visible thrombosis. In August 1992, repeat laparotomy was performed for intestinal obstruction associated with guarding. A $30 \mathrm{~cm}$ segment of infarcted ileum, thought to be caused by venous thrombosis, was resected. There were no bands and the small and large

TABLE I Abdominal investigations

\begin{tabular}{|c|c|c|c|}
\hline & \multicolumn{3}{|l|}{ Cases } \\
\hline & 1 & 2 & 3 \\
\hline $\begin{array}{l}\text { US } \\
\text { CT } \\
\text { MRI } \\
\text { Endosonography } \\
\text { ERCP } \\
\text { Gastroscopy } \\
\text { Colonoscopy } \\
\text { Angiograms }\end{array}$ & $\begin{array}{l}\text { Heterogeneous pancreatic head } \\
\text { Heterogeneous pancreatic head } \\
\text { Heterogeneous pancreatic head } \\
\text { Heterogeneous pancreatic head } \\
\text { N } \\
\text { Ulcerations } \\
8 \text { mm polyp } \\
\text { N† }\end{array}$ & $\begin{array}{l}\mathrm{N} \\
\mathrm{N} \\
\mathrm{ND} \\
\mathrm{N} \\
\mathrm{N} \\
\text { Ulcerations*} \\
\mathrm{N} \\
\mathrm{ND}\end{array}$ & $\begin{array}{l}\mathbf{N} \\
\mathbf{N} \\
\mathrm{ND} \\
\mathrm{N} \\
\mathrm{ND} \\
\text { Varix } \\
\mathrm{N} \\
\mathrm{N}+\end{array}$ \\
\hline $\begin{array}{l}\text { Amylasaemia } \\
\text { Lipasaemia }\end{array}$ & $\stackrel{N}{N D}$ & $\begin{array}{l}\mathbf{N} \\
\mathbf{N}\end{array}$ & $\begin{array}{l}\mathrm{N} \\
3.5 \mathrm{~N}\end{array}$ \\
\hline Laparotomy & $\mathbf{N}$ & $\mathbf{N}$ & $\mathrm{N}$ \\
\hline
\end{tabular}

US=ultrasonography; $M R I=$ magnetic resonance imaging; $C T=$ computed tomography; $\mathrm{ERCP}=$ endoscopic retrograde cholangiography and wirsungography. ${ }^{\star}$ Duodenal erosions (case 1); antral and duodenal erosions (case 2); tnormal apart from the mesenteric thrombosis; $\mathrm{N}=$ normal or negative result; $\mathrm{ND}=$ not done. intestines were not volvulated. Histopathological examination showed haemorrhagical infarction with numerous recent thrombosis of the veins in the submucosa and of larger mesenteric veins. The patient was given heparin postoperatively and made an uneventful recovery. Research for haematological disease was negative (Table II). Coumarin therapy was started. No relapse was seen at the last follow up visit in September 1994.

\section{Case report 3}

A 54 year old man was admitted to hospital in November 1991 for acute abdominal pain. There was a history of appendicectomy, hyperlipidaemia, angina pectoris, hypertension, and unexplained thrombosis of the radial artery in 1986. There was no history of thrombosis in the family. Drugs taken by the patient included: fenofibrate, nifedipin, and bisoprolol. Clinical findings included hypogastric pain, vomiting, blood per anum, and fever $\left(39^{\circ} \mathrm{C}\right)$. The abdomen was tender to examination without guarding. The white blood count showed leucocytosis and transient hyperthrombocytaemia $(570000 / \mu \mathrm{l})$. Serum lipase was 3.5 times normal, while amylase was normal. Ultrasonography, computed tomography, upper gastrointestinal endoscopy, colonoscopy, and barium gastroduodenal follow through were normal. As pain persisted, repeat ultrasonography was performed four months later and showed portal vein thrombosis. Intestinal angiograms showed thrombosis of the splenic and mesenteric veins as well. The pancreas was normal on computed tomography and endosonography. Two months later he had abdominal pain consistent with Koenig's syndrome. A barium swallow with follow through showed a short jejunal stricture $(2 \mathrm{~cm})$, associated with proximal dilatation (Fig 2). Distended intestinal loops were found on laparotomy and thought to be caused by a stricture of ischaemic origin. Distant from the stricture, a peritoneal band was found, which was resected along with the stricture. Histopathological examination showed a non-ulcerated stenosis with nonspecific inflammatory infiltrate. In submucosa and mesentere, vein walls were thickened by

TABLE II Haematological investigations

\begin{tabular}{llll}
\hline & \multicolumn{2}{l}{ Cases } & \\
\cline { 2 - 4 } & 1 & 2 & 3 \\
\hline Bone marrow culture $^{\star}$ & $N$ & $N$ & $N$ \\
Platelets & $\mathbf{N}$ & $\mathbf{N}$ & $\mathbf{N} \dagger$ \\
Protein S & $\mathbf{N}$ & $\mathbf{N}$ & $\mathbf{N}$ \\
Protein C & $\mathbf{N}$ & $\mathbf{N}$ & $\mathbf{N}$ \\
AT III & $\mathbf{N}$ & $\mathbf{N}$ & $\mathbf{N}$ \\
PT, APT & $\mathbf{N}$ & $\mathbf{N}$ & $\mathbf{N}$ \\
Factors II, V, VII, and X & $\mathbf{N}$ & $\mathbf{N}$ & $\mathbf{N}$ \\
Fibrinogen & $\mathbf{N}$ & $\mathbf{N}$ & $\mathbf{N}$ \\
Plasminogen & $\mathbf{N D}$ & $\mathbf{N}$ & $\mathbf{N}$ \\
Euglobulin lysis & $\mathbf{N D}$ & $\mathbf{N}$ & $\mathbf{N}$ \\
After venous occlusion & $\mathbf{N D}$ & $\mathbf{N}$ & $\mathbf{N}$ \\
Ham-Dacie test & $\mathbf{N}$ & $\mathbf{N D}$ & $\mathbf{N}$ \\
Circulating anticoagulants & $\mathbf{N}$ & $\mathbf{N}$ & $\mathbf{N}$ \\
Antiphospholipid antibodies & $\mathbf{+}$ & $\mathbf{N}$ & $\mathbf{N}$ \\
Anticardiolipin antibodies & $\mathbf{N}$ & $\mathbf{N}$ & $\mathbf{N}$ \\
& & &
\end{tabular}

$\mathrm{N}$ : normal or negative result; ${ }^{\star}=$ without addition of erythropoietin; $t=$ transiently increased; $\ddagger=$ transiently positive; AT III = antithrombin III; PT = prothrombin time; APT = activated partial thromboplastin time; $\mathrm{ND}=$ not done. 
fibrosis, which contained neovascularisation. This pattern was consistent with previous venous thrombosis with secondary repoermabilisation but no recent thrombosis was seen. The postoperative course was uneventful. Haematological tests were negative (Table II). The patient was treated longterm with coumarin in December 1992. No relapse was seen at the last follow up visit in September 1994.

\section{Discussion}

Mesenteric vein thrombosis is a rare disease. Diagnosis, and the research of causative factors, are difficult. Recognised promoting factors include pancreatitis, ${ }^{10}$ intra-abdominal or haematological causes, ${ }^{145}$ a patent or latent myeloproliferative syndrome, ${ }^{411}$ protein $C^{12} 13$ or $\mathrm{S},{ }^{14}$ or antithrombin $\mathrm{III}^{15}$ or plasminogen activator ${ }^{16}$ deficiencies. In one case associated with intestinal stricture, thrombosis was secondary to a deficit of the cofactor II or heparin. ${ }^{2}$ Antiphospholipid antibodies were transiently noted in our case 1 ; no signs of systemic lupus erythematosus were seen either at the time of admission or during follow up. These antibodies have been associated with mesenteric vein thrombosis. ${ }^{17}$ This patient (case 1) had ceased to be a drug addict, which can cause intestinal infarction without thrombosis, ${ }^{18}$ long before the present episode of thrombosis occurred.

Signs of chronic intestinal obstruction appeared several weeks after the presumed onset of mesenteric vein thrombosis in all three cases, but the formal diagnosis of intestinal obstruction was made only several weeks to several months afterwards. In one patient receiving heparin, the diagnosis of mural haematoma was wrongly considered. In the two patients for whom barium follow through studies were obtained, the image was of a short $(2 \mathrm{~cm})$ or long $(5 \mathrm{~cm})$ regularly contoured stricture (Figs 1 and 2). Cardot et $a l^{2}$ saw a moderately tight, $15 \mathrm{~cm}$ long stricture in the proximal intestine, with spiculed borders. Witte $e t a l^{6}$ reported the acute onset of ascites and mesenteric and portal vein thrombosis in a 71 year old man. Later, a barium follow through showed oedema, spicules, thumb prints in the distal ileum. No pathological data were provided in either of these cases.

In our patients, the anatomical lesions were diversified, suggesting that they corresponded to different stages of intestinal involvement. Mucosal ulceration was found only in two patients operated on early after the onset of symptoms.

Anticoagulation treatment was started because no curable cause of thrombosis could be found (Tables I and II). With anticoagulation treatment, all patients have been free of recurrent thrombosis, suggesting the use of longterm anticoagulation treatment for this condition.

In all three patients, the stricture of the small intestine developed during the post-thrombotic course, and became symptomatic, requiring surgical resection. After surgery, there has not been any further bowel disease.

Intestinal strictures, associated with mesenteric vein thrombosis, are probably the consequence of ischaemia because of the following findings. Firstly, in our patients, a two stage sequence was found. Acute abdominal pain and fever, accompanied in two cases by blood from the anum were the initial manifestations. This corresponds to the initial ischaemia. ${ }^{2} 36-8$ Secondly, regularly contoured stricture is consistent with ischaemia. The roentgenoligical signs reported by Cardot $e t a l^{2}$ and Witte $e t a l^{6}$ also suggest an ischaemic mechanism. Thirdly, in our patients, histological examination confirmed the mucosal (ulcerations in two cases) and submucosal (fibrosis or oedema and haemorrhage) involvement. Ischaemia is further supported by the occlusion of neighbouring vessels.

Surprisingly, strictures are rarely mentioned in reports of mesenteric vein thrombosis. The reason is not obvious. Two of our patients had taken aspirin just before the initial manifestations. By analogy with lesions attributed to non-steroid anti-inflammatory drug treatment, ${ }^{19}$ it might be hypothesised that these drugs played a part in the constitution of the intestinal lesions. This should not obscure the fact, however, that the complete occlusion of the small mesenteric vessels is an indisputable proof of primary vascular involvement. In all our three cases, the surgeon noted a peritoneal band in contact with the stricture, but the intestine was neither the site of volvulus or strangulation. The implications of associated bands remain a mystery, but they might be related to subacute torsion, a possible cause of mesenteric vein occlusion, as we have previously reported. ${ }^{20}$

The diagnosis of mesenteric vein thrombosis associated with intestinal stricture could probably be made more often and earlier if only the clinician were aware of its possibility. This would lead to an aetiological inquiry, intestinal resection whenever necessary, and anticoagulation, as indicated.

We would like to thank Catherine Collet, MD, Florence Mathonnet, $\mathrm{PhD}$, Thi Vu, MD (Poissy), and Marie-Hélène Horellou, MD (Paris) for their assistance in the haematological investigations, Nicole Casadevall, MD (Garches) for the bone investigations, Nicole Casadevall, MD (Garches) for the bone
marrow cultures and I Bad Alsamed, MD (Paris) for the patholmarrow cultures and
ogy study in case 1 .

1 Grendell JM, Ockner RK. Mesenteric venous thrombosis. Gastroenterology 1982; 82: 358-72.

2 Cardot F, Borg JY, Guédon C, Lerebours E, Colin R. Les syndromes d'ischémie veineuse mésentérique: infarctus et ischémie transitoire. Gastroenterol Clin Biol 1992; 16: 644-8.

3 Harward TRS, Green D, Bergan JJ, Rizzo RJ, Yao JST. Mesenteric vein thrombosis. F Vasc Surg 1989; 9: Mesenteric

4 Valla D, Casadevall N, Huisse MG, Tulliez M, Grangé JD, Muller O, et al. Etiology of portal venous thrombosis in adults. A prospective evaluation of primary myeloproliferative disorders. Gastroenterology 1988; 94: 1063-9.

5 Marzelle J. Thromboses portale et mésentérique. Etiologie manifestations cliniques et traitement. Ann Gastroentero Hépatol 1990; 26: 51-60.

6 Witte CL, Brewer ML, Witte MH, Pond GB. Protean manifestations of pylethrombosis. A review of thirty-four patients. Ann Surg 1985; 86: 191-202.

7 Verbanck JJ, Rutgeerts LJ, Haerens MH, Tytgat JH, Segaert MF, Tytgat $\mathrm{HF}$, et al. Partial splenoportal and superior mesenteric venous thrombosis. Early sonographic mesenteric venous thrombosis. Early sonographic diag nosis and successful conservat

8 Clavien PA, Huber O, Rohner A. Venous mesenteric ischemia: conservative or surgical treatment? Lancet 1989; ii: 48 . 
9 Grieshop RJ, Dalsing MC, Cikrit DF, Lalka SG, Sawchuk AP. Acute mesenteric venous thrombosis. Revisited in a time of diagnostic clarity. Am Surg 1991; 57: 573-8.

10 Bernades P, Baetz A, Levy P, Belghiti J, Menu Y, Fékété F. Splenic and portal venous obstruction in chronic Splenic and portal venous obstruction in chronic
pancreatitis. A longitudinal study of a medical-surgical series of 226 patients. Dig Dis Sci 1992; 37: 340-6.

11 Cardin F, Graffeo M, McCormick PA, McIntyre N, Burroughs A. Adult 'idiopathic' extrahepatic venous thrombosis. Importance of putative 'latent' myeloproliferative disorders and comparison with cases with known etiology. Dig Dis Sci 1992; 37: 335-9.

12 Pabinger-Fasching I, Bertina RM, Lechner K, Niessner H, Korninger $\mathrm{C}$ Protein $\mathrm{C}$. lies. Thromb Haemost 1983; 50: 810-3.

13 Theodore C, Dosquet C, Boin-Marchal MA, HaguelHermitte $\mathrm{H}$, Renaud J. Infarctus veineux mésentérique et déficit en protéine C [Letter]. Gastroenterol Clin Biol 1989; 13: 226-7

14 Broekmans AW, van Rooyen W, Westerveld BD, Briet E, Bertina RM. Mesenteric vein thrombosis as presenting manifestation of hereditary protein $S$ deficiency. Gastroenterology 1987; 92: 240-2.
15 Wilson C, Walker ID, Davidson JF, Imrie CW. Mesenteric vein thrombosis and antithrombin III deficiency. $\mathcal{f}$ Clin Pathol 1987; 40: 906-8.

16 Boyko OB, Pizzo SV. Mesenteric vein thrombosis and vascular plasminogen activator. Arch Pathol Lab Med

17 Cappell MS, Seibold JR. Mesenteric thrombosis associated with anticardiolipin antibodies in a patient with systemic lupus erythematosus. $A m \mathcal{F}$ Gastroenterol 1992; 87: $520-2$.

18 Freudenberger RS, Cappell MS, Hutt DA. Intestinal infarction after intravenous cocaine administration. Ann Intern Med 1990; 113: 715-6.

19 Allison MC, Howatson AG, Torrance CJ, Lee FD, Russell RI. Gastrointestinal disease associated with the use of non steroidal antiinflammatory drugs. $N$ Engl $\mathcal{f}$ Med 1992; 327: 749-54.

20 Eugène $\mathrm{C}$, Wesenfelder L, Lopez Y, Gallic MC, Anciaux ML. Thrombose mésentérique survenant chez un malade porteur d'un mésentère commun et splenectomisé pour maladie de Minkowski-Chauffard. Succès apparent de l'héparine. Gastroenterol Clin Biol 1991; 15: 366-8. 